\title{
Projected Salt Waste Production from a Commercial Pyroprocessing Facility
}

\author{
Michael F. Simpson \\ Idaho National Laboratory, P.O. Box 1625, Idaho Falls, ID 83415, USA \\ Correspondence should be addressed to Michael F. Simpson; michael.simpson@inl.gov
}

Received 20 February 2013; Accepted 24 April 2013

Academic Editor: Candido Pereira

Copyright @ 2013 Michael F. Simpson. This is an open access article distributed under the Creative Commons Attribution License, which permits unrestricted use, distribution, and reproduction in any medium, provided the original work is properly cited.

\begin{abstract}
Pyroprocessing of used nuclear fuel inevitably produces salt waste from electrorefining and/or oxide reduction unit operations. Various process design characteristics can affect the actual mass of such waste produced. This paper examines both oxide and metal fuel treatment, estimates the amount of salt waste generated, and assesses potential benefit of process options to mitigate the generation of salt waste. For reference purposes, a facility is considered in which $100 \mathrm{MT} / \mathrm{year}$ of fuel is processed. Salt waste estimates range from 8 to $20 \mathrm{MT} /$ year from considering numerous scenarios. It appears that some benefit may be derived from advanced processes for separating fission products from molten salt waste, but the degree of improvement is limited. Waste form production is also considered but appears to be economically unfavorable. Direct disposal of salt into a salt basin type repository is found to be the most promising with respect to minimizing the impact of waste generation on the economic feasibility and sustainability of pyroprocessing.
\end{abstract}

\section{Introduction}

Pyroprocessing is currently being developed by several nations (including but not limited to the USA, Republic of Korea, Russia, and India) for potential implementation in a large-scale, commercial fuel cycle. In most cases, this is driven by the process' deemed compatibility with a fast reactor. There is also a nonproliferation element to its attractiveness. Japan is the only nuclear nonproliferation Treaty (NPT) nonnuclear weapons state that possesses full-scale nuclear fuel reprocessing facilities. They use a PUREX-based process to coextract uranium and plutonium from their spent fuel. Due to the potential to adapt this process to extract weapons-grade plutonium, Japan's use of the technology has come under widespread international criticism. In an effort to avoid such controversy, the Republic of Korea has been developing pyroprocessing since 1997 for the purpose of closing the fuel cycle and managing their used fuel stockpiles [1]. Pyroprocessing has been viewed as being significantly less versatile with respect to producing weapons-grade materials. Another attractive feature is that the process can be designed into compact facilities colocated on reactor sites to minimize the risk of transporting used nuclear fuel on public transportation routes. In the Republic of Korea (South Korea), pyroprocessing is the only used fuel management technology option currently being considered because of the diplomatic situation on the Korean peninsula.

The pyroprocessing flowsheet is conceptually simple with a limited number of unit operations. A sample flowsheet that could be used for treating either oxide or metal fuel is shown in Figure 1. Unit operations are included for selectively removing fission products from electrorefiner salt (zeolite columns), producing waste forms (ceramic waste furnace and metal waste furnace), and distilling salt from actinide products (cathode processor).

One potential application for this process would be to treat used oxide fuel from wet storage facilities at commercial light water reactor sites. Processing this fuel would be considered an alternative to continued on-site dry storage or permanent disposal in a geologic repository. As laid out in Figure 1, the process generates one product (actinide metals) and has two waste streams (high-level ceramic waste and high-level metal waste). The actinide metals could be used to fabricate fresh fuel for a fast reactor. The waste products are designated as high-level waste by the US legal definition. Until recently, 


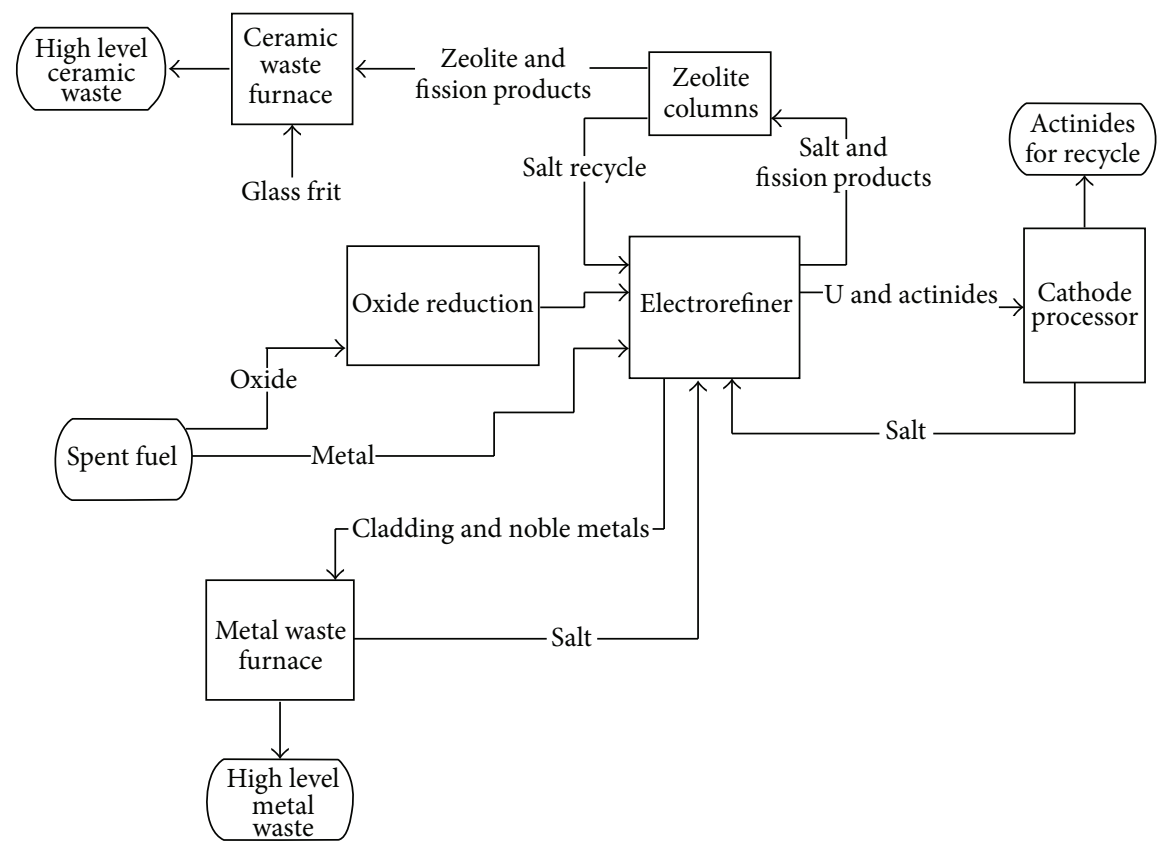

FIGURE 1: Sample flowsheet for pyroprocessing.

high-level radioactive waste (HLW) was intended to be disposed of in a permanent geologic repository in Yucca Mountain (Nevada). At this time, the U.S. DOE has cancelled the Yucca Mountain nuclear waste repository project, and there is currently no path for permanent disposal of used nuclear fuel or byproducts of nuclear fuel reprocessing (HLW).

The HLW ceramic from Figure 1 can for all practical purposes be referred to as the salt waste. During the development of the Integral Fast Reactor (IFR) and later the EBRII Spent Fuel Treatment (SFT) process, it was established that the salt waste could be stabilized in zeolite followed by conversion to glass bonded sodalite [2-4]. In the IFR-based pyroprocessing flowsheet, electrorefiners use molten $\mathrm{LiCl}$ $\mathrm{KCl}$ in a eutectic composition as their electrolyte. Uranium trichloride is another essential component in this salt. When the used fuel is immersed into the salt, $\mathrm{UCl}_{3}$ oxidizes active metals in the fuel-including metallic sodium used to bond the fuel to the cladding, rare earth fission products, minor actinides including plutonium, and Group I/II fission products. All of these elements are converted to chloride salt and partition into the molten $\mathrm{LiCl}-\mathrm{KCl}$ salt pool. When it is necessary to remove some of the salt and prepare it for waste disposal, it is first milled to a powder or fine particulate. It is then blended with dehydrated zeolite $-4 \mathrm{~A}$ at $500^{\circ} \mathrm{C}$, which immobilizes the salt into the zeolite's microscopic pores. The salt-loaded zeolite is cold-blended with glass frit powder followed by thermally induced consolidation at a temperature up to $950^{\circ} \mathrm{C}$ [5]. The zeolite- $4 \mathrm{~A}$ converts to sodalite during the consolidation. This glass-bonded sodalite is designated as ceramic waste, given that the waste forms are monolithic ceramic in consistency. Ceramic waste form samples were generated during the EBR-II SFT demonstration project and shown to be more corrosion resistant than a reference glass waste form that had been developed for immobilizing reprocessing wastes at the Savannah River Site [6]. The ceramic waste form and other waste form options will be further discussed in a later section of this paper.

In addition to the electrorefiner, the oxide reduction unit operation can also be the source of salt waste in a pyroprocessing facility. If oxide fuel is being used as the process feed, it must be reduced to metallic form prior to loading into the electrorefiner. Such reduction is accomplished either via reaction of a reducing metal or via electrolytic reductionboth in a molten chloride salt pool $[7,8]$. Currently, the electrolytic process is generally favored. It utilizes an $\mathrm{LiCl}-$ $\mathrm{Li}_{2} \mathrm{O}$ salt operating at $650^{\circ} \mathrm{C}$. Certain fission products in the used fuel (Cs, Sr, and $\mathrm{Ba}$ most notably) partition into the salt phase during electrolytic reduction of the used fuel [8]. When the concentration of those fission products exceeds the operating limit for the process, it is necessary to bleed out some of the used salt and replace it with clean $\mathrm{LiCl}-\mathrm{Li}_{2} \mathrm{O}$, thus reducing the concentration of the fission products. This salt waste has been considered to be particularly problematic to researchers developing pyroprocessing, due to the relatively high melting point of the LiCl-based oxide reduction salt. Occlusion of this salt by the zeolite is considered to be more challenging than the LiCl-KCl-based salt used in electrorefiners because of its higher melting point $\left(610^{\circ} \mathrm{C}\right.$ versus $350^{\circ} \mathrm{C}$ for eutectic $\mathrm{LiCl}-\mathrm{KCl}$ ). Another likely problem with making ceramic waste from the oxide reduction salt is the high generation of radioactive decay heat from Cs-137 and Sr-90. Ceramic waste forms can be considered to be thermal insulators and thus can be prone to excessive heat buildup when loaded with Cs and Sr unless the waste forms are kept relatively small. 
TABLE 1: Major contaminants of the electrorefiner and oxide reducer.

\begin{tabular}{lc}
\hline Electrorefiner & Oxide reducer [8] \\
\hline $\mathrm{Na}$ & $\mathrm{Cs}$ \\
Rare earths $(\mathrm{Ce}, \mathrm{Pr}, \mathrm{Sm}, \mathrm{Pm}, \mathrm{Nd}, \mathrm{Eu}, \mathrm{Gd})$ & $\mathrm{Sr}$ \\
Group I $(\mathrm{Cs}, \mathrm{Rb})$ & $\mathrm{Ba}$ \\
Group II $(\mathrm{Sr}, \mathrm{Ba})$ & $\mathrm{Te}$ \\
Group III $(\mathrm{La}, \mathrm{Y})$ & \\
\hline
\end{tabular}

TABLE 2: Nominal composition of sodium-bonded metal used fuel.

\begin{tabular}{lc}
\hline Component & Mass fraction \\
\hline $\mathrm{Pu}$ & 0.01 \\
$\mathrm{Na}$ (bonding) & 0.02 \\
Active metal fission products (includes Group & 0.04 \\
I/II/III and rare earths) & 0.93 \\
$\mathrm{U}$ & \\
\hline
\end{tabular}

\section{Analysis of Salt Waste Production}

In this section, the primary objective is to provide estimates under a variety of scenarios for the mass of salt waste that would be generated from a large-scale, commercial pyroprocessing facility. Both electrorefiner salt waste and oxide reduction salt waste is considered. To the extent possible, generic processes are considered. The point of this analysis is not to make precise predictions based on current technology, but rather it is to provide an estimate of the limiting conditions and to quantify the potential benefit from specific technology improvements.

2.1. Limiting Factors. There are a number of factors that can dictate the need to remove and dispose of salt from an electrorefiner or an oxide reducer. These include total mass or volume of the salt, heat generation from the fission product decay, fission product concentration, and plutonium inventory. There are important differences between the electrorefining and oxide reduction processes, including the elements that partition into their salt phases. Table 1 summarizes the behavior of key elements in each of these systems. Salt inventory limits would be based on the number of units in a facility and maximum volume per unit. For this analysis, it is assumed that the facility operates in startup mode for some period of time before one or more of the limits are reached. The duration of this startup period is not important, and the ultimate decommissioning of the pyroprocessing facility is not considered.

2.2. Metal Fuel Processing. First, consider metallic fuel processing. This only requires operation of the electrorefiner (ER). The oxide reduction (OR) system is not needed in this case. Practically speaking, plutonium inventory should not be considered a limiting factor in an ER, since a commercial facility would almost certainly recover plutonium for fuel fabrication. The rate of the plutonium recovery could match the rate of it being fed into the ER. Since fission product decay heat and fission product concentration are directly related, there are essentially two factors to consider for the ER-total mass of salt and total concentration of fission products in the salt.

Consider the point when all of the electrorefiners in a pyroprocessing facility reach their salt limit-whether defined based on total mass or concentration of fission products (FPs). From that point onward, an amount of salt proportional to the processing rate of fuel will need to be pulled out of the ER. Salt waste can be directly correlated with fuel processed. Mass in the salt phase increases due to accumulation of minor actinides, sodium, and fission products. The chloride ions in the salt molecules must also be counted. Those chloride ions come from $\mathrm{UCl}_{3}$ which is added to the ER salt. The $\mathrm{UCl}_{3}$ would likely be produced within the facility and be mixed with $\mathrm{LiCl}-\mathrm{KCl}$. Nominally, it can be assumed that the $\mathrm{UCl}_{3}$ would be contained in an $\mathrm{LiCl}-\mathrm{KCl}-\mathrm{UCl}_{3}$ mixture consisting of $75 \mathrm{wt} \% \mathrm{UCl}_{3}$. Thus, with every batch of fuel added to the ER it is necessary to calculate the mass of $\mathrm{LiCl}-\mathrm{KCl}-\mathrm{UCl}_{3}$ added as well as the mass of fission product, sodium, and transuranic chlorides that would form. The mass of $\mathrm{U}$ from the $\mathrm{LiCl}-\mathrm{KCl}-\mathrm{UCl}_{3}$ can be neglected, since it is reduced to metal during the process of oxidizing active metals from the fuel and is subsequently electrochemically recovered from the ER. The following formula can be generally applied:

$$
\begin{aligned}
M_{\text {salt waste }}= & M_{\mathrm{NaCl}}+M_{\mathrm{FP} \text { salts }}+M_{\mathrm{TRU} \text { salts }} \\
& +M_{\text {oxidant salt }}-M_{\mathrm{U} \text { oxidant }} .
\end{aligned}
$$

Calculations require detailed fuel composition, which cannot be bracketed for all potential scenarios. For illustrative purposes, however, consider the nominal composition given in Table 2.

Two demonstrated processes can be used to minimize the mass of salt waste generated-U/TRU recovery and sodium distillation. U/TRU recovery can be accomplished via deposition on a liquid cadmium cathode (LCC) or via drawdown using a reducing metal [9-11]. Ideally using such processes, all of the $\mathrm{Pu}$ and other minor actinides in the used fuel could be kept out of the salt waste stream and recovered for use in fabricating new fuel elements. Sodium distillation could be performed after fuel chopping but prior to electrorefining and would result in the majority of the sodium metal being removed from the fuel. For high burnup fuel, a fraction of the sodium has been found to be inseparable via distillation. Table 3 gives the salt waste calculations for the nominal fuel given in Table 2 under the four possible scenarios involving $\mathrm{Pu}$ and $\mathrm{Na}$. For a facility that processes $100 \mathrm{MT}$ of used sodium bonded fuel per year, the mass of salt waste generated is estimated to range from 12.3 to $21.7 \mathrm{MT}$. For this exercise, the glass-bonded sodalite is assumed to be the waste form of choice. Salt content in the sodalite waste form is approximately $7.5 \mathrm{wt} \%$. It can thus be calculated that the ceramic waste mass per year would range from 164 to 289 MT. Clearly, sodium removal should be pursued as a technically simple process with a substantial waste minimization benefit. While $\mathrm{Pu}$ should be recycled for the sake of fabricating new fuel elements, its removal results in a relatively insignificant reduction in waste. However, if 
TABLE 3: Salt waste calculations based on nominal composition and total mass limit.

\begin{tabular}{lcccc}
\hline Case & Pu recycle & Sodium removal & Mass of salt waste per mass of fuel & Mass of ceramic waste per mass of fuel \\
\hline 1 & No & No & 0.217 & 2.89 \\
2 & No & Yes & 0.133 & 1.77 \\
3 & Yes & No & 0.207 & 2.76 \\
4 & Yes & Yes & 0.123 & 1.64 \\
\hline
\end{tabular}

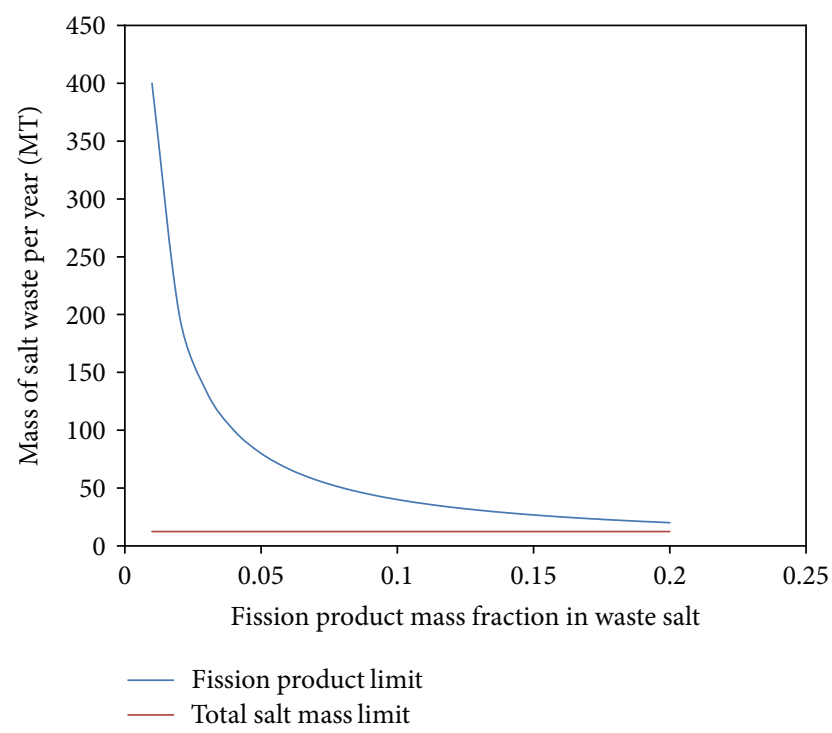

FIGURE 2: Estimated ER salt waste mass per year for a $100 \mathrm{MT} /$ year used metal fuel pyroprocessing facility considering cases where the ER is fission product limited or total salt mass limited and only salt throw-away is pursued.

the $\mathrm{Pu}$ was not recovered, its limiting concentration could dictate a higher rate of salt removal from the ER. Case 4 in Table 3 should be considered the ideal situation-a true minimum with respect to waste production based on the fuel composition given in Table 2.

Alternatively, consider the case where fission product concentration in the ER salt may be the limiting factor. This could be based upon melting point of the salt, fission product decay heat, or contamination of actinide deposits. If this analysis indicates less salt waste production than 12.3 MT per $100 \mathrm{MT}$ of fuel, then the minimum would revert to that level. If a higher salt waste production rate were identified based on fission product removal, then that higher rate would be established as the new minimum.

The key variable for assessing the salt waste mass production due to fission product removal is what the maximum fission product concentration is for the salt. This would likely range between 5 and $20 \mathrm{wt} \%$. As previously mentioned, this could be based upon the liquidus temperature of the salt, heat from decay, or contamination of actinide products. Detailed consideration of these factors is not in the scope of this paper, as it requires extensive and costly experimentation. For any commercial facility being designed, salt limit tests would be an important prerequisite for completion of the design. Rather the entire range was considered and included

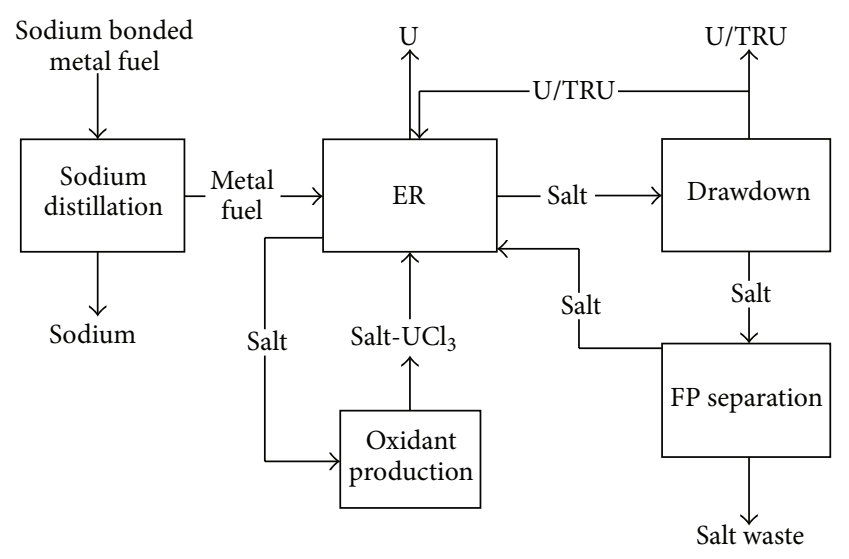

FIGURE 3: Used metal fuel pyroprocessing flowsheet involving selective separation of actinides and fission products from electrorefiner Salt.

in the plot shown in Figure 2. As can readily be seen from this plot, the fission product removal dictates a higher rate of salt waste generation unless the salt can be allowed to run at contamination levels in excess of $20 \mathrm{wt} \%$ fission products.

The previous analysis considers only disposal of salt as an option for dealing with ER salt processing limits. What if selective chemical separations processes are employed? Could the amount of waste generated from pyroprocessing of used nuclear fuel be substantially reduced? In particular, consider two types of processes-actinide drawdown and fission product removal. The former is used to virtually eliminate the U/TRU chlorides from the salt with a variety of approaches feasible (electrolysis, reaction with reducing metal, oxidation induced precipitation, and molten liquid extraction). The latter is then employed to extract fission product chlorides from the salt. Again, a number of processes have been developed for that purpose, including zeolite ion exchange, oxygen sparging, and phosphate precipitation [1214]. To model the potential impact of these two separations processes, the flowsheet shown in Figure 3 was considered.

In modeling the flowsheet shown in Figure 3, it was assumed that the sodium distillation and drawdown processes are both $100 \%$ efficient. In order to consider a wide range of fission product separation processes, a generic unit operation was modeled in which the efficiency is defined based on the amount of $\mathrm{LiCl}-\mathrm{KCl}$ that is effectively carried along with the fission products:

$$
\chi=\frac{M_{\mathrm{LiCl}-\mathrm{KCl} \text { waste }}}{M_{\mathrm{FP} \text { chlorides }}} .
$$




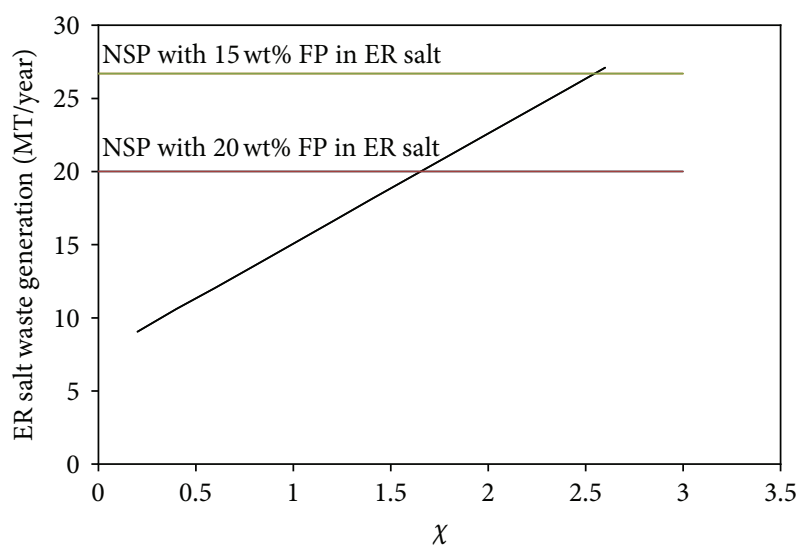

FIGURE 4: Comparison of ER salt waste generation rates for a $100 \mathrm{MT} /$ year facility using selective process (black curve) versus nonselective process (NSP) with two different levels of fission product accumulation in the electrorefiner for used metal fuel processing.

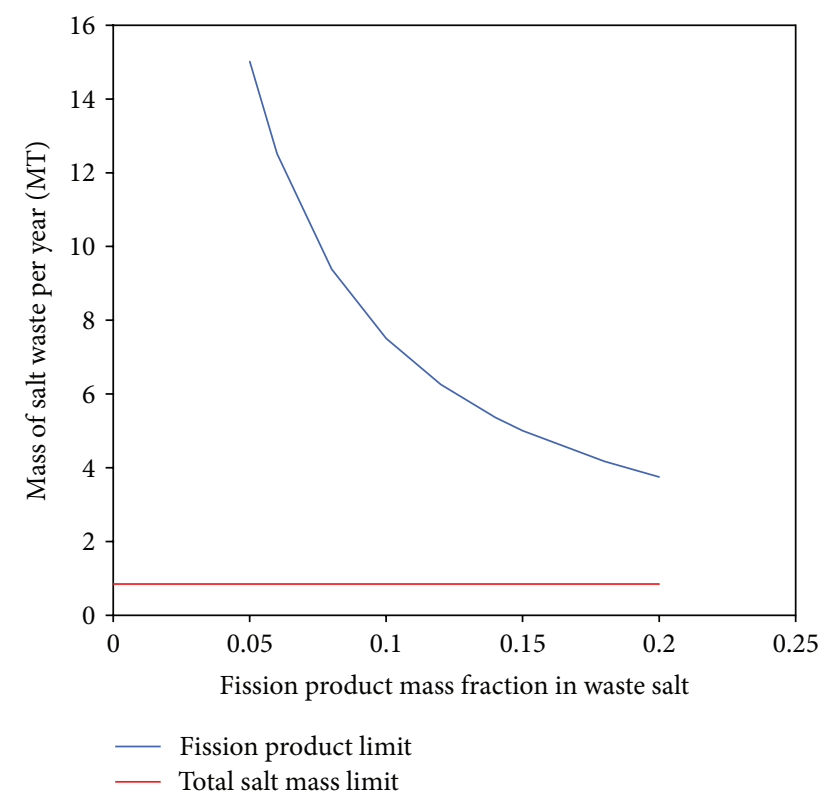

FIGURE 5: Estimated OR salt waste mass per year for a 100 MTHM/ year pyroprocessing facility considering cases where the $\mathrm{OR}$ is fission product limited or total salt mass limited and only salt throwaway is pursued.

The mass of waste salt was calculated for various values of this ratio and plotted in Figure 4. A comparison between the selective process and the nonselective process (NSP) is shown in this plot. If the NSP can be run with the ER fission product concentration of $20 \mathrm{wt} \%$, then the $\chi$ value must be about $1.6 \mathrm{or}$ less to show an improvement. If the NSP can be run at $15 \mathrm{wt} \%$ fission products in the ER, then the $\chi$ value would need to be 2.6 or less. This can also be viewed in terms of the effective concentration of the fission product stream coming out of the selective process. The key to waste minimization is to minimize the amount of $\mathrm{LiCl}-\mathrm{KCl}$ discarded during the waste process. For an ideal separation process, only about 7.5 MT of
TABLE 4: Nominal composition of oxide used fuel. Mass fraction calculated on metal basis (oxygen neglected). Composition based on ORIGIN calculation of $33 \mathrm{MWd} / \mathrm{kg}$ burn-up, 10-year decayed fuel.

\begin{tabular}{lc}
\hline Component & Mass fraction \\
\hline $\mathrm{U}$ & 0.974 \\
$\mathrm{TRU}$ & 0.010 \\
$\mathrm{Cs}$ & 0.0023 \\
$\mathrm{Sr}$ & 0.00080 \\
$\mathrm{Ba}$ & 0.0020 \\
Other active metal fission products $^{*}$ & 0.011 \\
\hline
\end{tabular}

${ }^{*}$ Rare earths, Group III, and Rb.

salt waste (all fission product chlorides) would be generated per $100 \mathrm{MT}$ of metallic fuel. Bracketing the other end of the spectrum with nonselective processes, up to 20-27 MT of salt waste would be generated for the same amount of fuel. This clearly motivates the development and implementation of selective fission product separation processes.

2.3. Oxide Fuel Processing. Oxide fuel must first be converted to metallic form using an oxide reduction (OR) unit operation before it is fed into an electrorefiner. In contrast to metallic fuel, there would be no metal sodium to remove from the fuel prior to processing. The used fuel would essentially be uranium oxide $\left(\mathrm{UO}_{2}\right)$ with a variable amount of TRU and fission products mostly in oxide form. Actual TRU and fission product concentrations vary based on burn-up level of the fuel as well as cooling time after removal from the reactor. While the oxide reduction process is designed to simply convert oxide compounds to metals and leave all used fuel components in the fuel basket, some of the fission products have been found to partition into the molten $\mathrm{LiCl}-\mathrm{Li}_{2} \mathrm{O}$ electrolyte [8]. Most notably, this includes cesium, strontium, and barium. It is assumed that the following reactions occur during this process:

$$
\begin{gathered}
\frac{1}{2} \mathrm{Cs}_{2} \mathrm{O}+\mathrm{LiCl} \longrightarrow \mathrm{CsCl}+\frac{1}{2} \mathrm{Li}_{2} \mathrm{O} \\
\mathrm{SrO}+2 \mathrm{LiCl} \longrightarrow \mathrm{SrCl}_{2}+\mathrm{Li}_{2} \mathrm{O} \\
\mathrm{BaO}+2 \mathrm{LiCl} \longrightarrow \mathrm{BaCl}_{2}+\mathrm{Li}_{2} \mathrm{O}
\end{gathered}
$$

Assume the used oxide fuel nominally has the composition given in Table 4.

Similar to the ER, the salt processing limit for the OR would be dictated either by total mass of the salt or fission product concentration. In this case, only $\mathrm{Cs}, \mathrm{Sr}$, and $\mathrm{Ba}$ are considered to be fission products of interest. For a facility in which 100 MTHM (metric tons heavy metal) is processed each year, the plot in Figure 5 shows the amount of salt that would need to be disposed from the OR unit based on either the total salt mass limit or the fission product limit. The $x$-axis represents the maximum allowable mass fraction of fission product chlorides in the salt. The curve for the fission product limit case was calculated based on all of the cesium, strontium, and barium partitioning into the salt phase. The total salt mass limit curve is a constant based on the total 


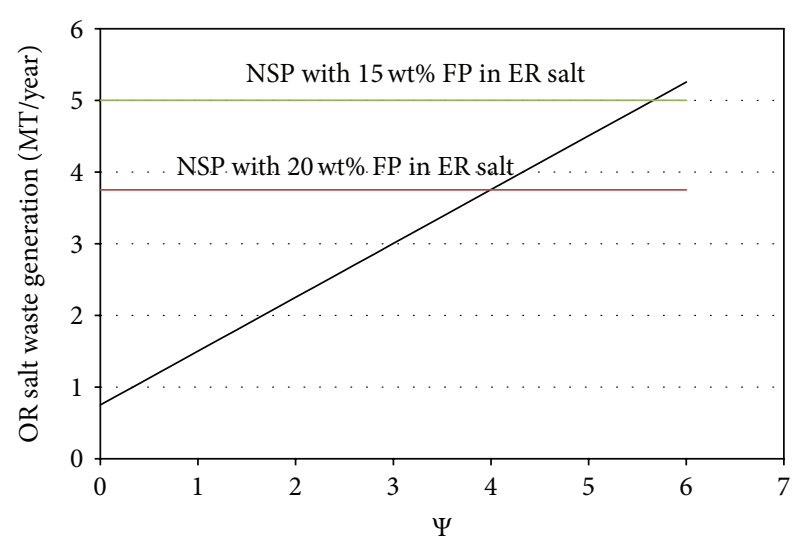

FIGURE 6: Comparison of OR salt waste generation rates for $100 \mathrm{MTHM} /$ year facility for selective process (black curve) to nonselective process (NSP) with two different levels of fission product accumulation in the OR.

mass added to the salt for 100 MTHM of spent fuel. Under achievable contamination levels in the OR salt, the fission product limit is more restrictive than the total salt mass limit.

As with the case of the ER salt disposal, there are selective separation processes that can be considered for removing $\mathrm{Cs}, \mathrm{Sr}$, and $\mathrm{Ba}$ from the OR salt without carrying as much other salt ( $\mathrm{LiCl}$ and $\mathrm{Li}_{2} \mathrm{O}$ in this case) with it. These generally are based on the mechanisms of selective precipitation, ion exchange, intercalation, surface complexation, or melt crystallization [15]. The flowsheet for oxide fuel treatment with selective salt separation would be nearly identical to that shown in Figure 3 but with the oxide reduction unit preceding the ER. Salt adhered to the reduced fuel from the OR could be distilled and returned to the OR. As with the analysis of selective separation processes for ER salt, it is simplest to characterize the selective separation process by a mass ratio rather than delve into the details of each processing option:

$$
\Psi=\frac{M_{{\mathrm{LiCl}-\mathrm{Li}_{2} \mathrm{O}}}\left(M_{\mathrm{CsCl}}+M_{\mathrm{SrCl}_{2}}+M_{\mathrm{BaCl}_{2}}\right)}{.}
$$

As can be seen in Figure 6, there is a large improvement in OR salt waste generation that can be achieved with only moderately selective fission product separation processes. The best possible salt waste generation rate for a very high $20 \mathrm{wt} \% \mathrm{FP}$ in the OR salt would be $3.75 \mathrm{MT} / \mathrm{year}$, while an ideal selective process would only generate $0.75 \mathrm{MT}$ of OR salt waste per year (all based on 100 MTHM fuel input per year). Selective processes with $\Psi$ values of less than 4 should be considered attractive for waste minimization.

There would also be ER salt waste generated from processing of oxide fuel. The OR only removes $\mathrm{Cs}, \mathrm{Sr}$, and $\mathrm{Ba}$ from the fission product inventory. The remaining fission products which are primarily in the rare earth family would partition into the ER salt. Applying the same selective process model as used for ER treatment of sodium bonded metal fuel, the plot in Figure 7 was generated. Interestingly, the removal of $\mathrm{Cs}, \mathrm{Sr}$, and $\mathrm{Ba}$ from the used fuel results in a much more favorable situation with respect to ER salt waste. Even without

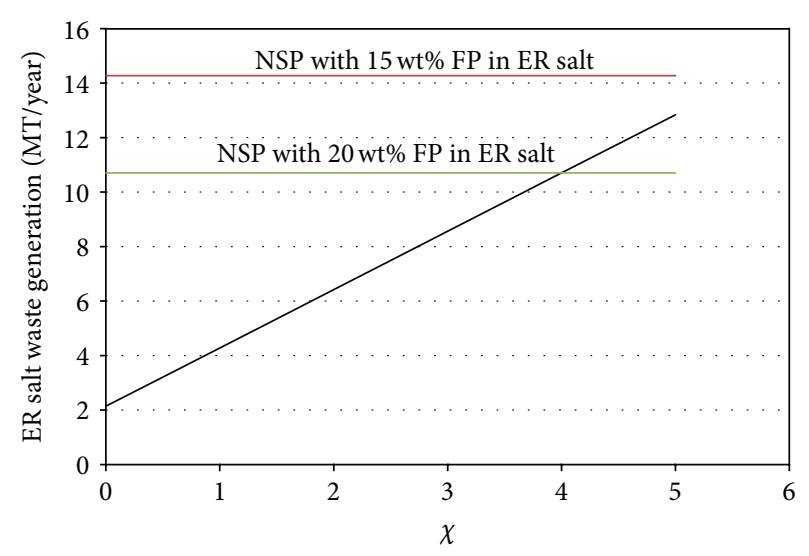

FIGURE 7: Comparison of ER salt waste generation rates for $100 \mathrm{MTHM} /$ year facility for selective process (black curve) to nonselective process (NSP) with two different levels of fission product accumulation in the ER.

using a selective process, waste generation rates are cut in half. And there is a substantially greater improvement that can be attained by using a selective FP removal process. The removal process does not need to be as selective as with the metal fuel in order to improve upon the salt bleed process.

Combining the OR and ER salt waste from oxide fuel yields 14.4 MT of salt waste per 100 MTHM fuel treated for the case where the fission product limits are set at $20 \mathrm{wt} \%$ and non-selective processing is employed. From examining Figures 6 and 7, it is reasonable to expect that this could be reduced to about $8 \mathrm{MT} /$ year via use of selective fission product separation. While these are estimates based on nominal fuel compositions and idealized processing assumptions, it does provide a basis for assessing the cost/benefit ratio of implementing FP separation technology. Conventional assumptions in this area have been that selective salt processing would have a much greater impact on salt disposal and perhaps lead to a near-zero waste facility. Based on these calculations, this does not appear to be a reasonable assumption.

\section{Waste Disposal}

The previous analysis calculates the mass of waste salt generated under various scenarios. But it does not consider the actual waste form of this salt that will be disposed. If the waste is truly in the form of chloride salt, consider three possible alternatives-glass bonded sodalite (GBS), glass, and direct disposal. The GBS waste form (also known as ceramic waste) was developed initially at Argonne National Laboratory for the Integral Fast Reactor (IFR) process [2-6]. It is produced by occluding the salt into zeolite-A, blending in glass frit, and thermally converting the glass/zeolite to glass-bonded sodalite. The process equipment and operating conditions are well understood for the ceramic waste process. But the drawback is that only about $7.5 \mathrm{wt} \%$ salt can be incorporated into the GBS. That would equate to as much as $187 \mathrm{MT}$ of ceramic waste per 100 MTHM of used oxide fuel. 
Alternatively, the salt could be incorporated into a pure glass waste form. Limited research has been performed on using tellurite glass to immobilize electrorefiner salt [16]. In this case, the glass can hold up to about $10 \mathrm{wt} \%$ salt-equating to a still considerable mass of waste (140 MT of glass waste for 100 MTHM of used oxide fuel).

For a nuclear fuel cycle to be considered appealing to the general public, it would seem that the mass of waste produced should be less than the mass of used fuel processed. This directs one to consider the most radical case of simply disposing of the salt without any added components or waste form processing. This is the direct disposal/no waste form option. Intuitively, this would seem like a nonstarter of an idea due to the extremely hygroscopic nature of the chloride salts. These salts will pick up substantial quantities of water by simply being in contact with humid air. They have a high solubility in water. It would seem that they would be considered completely inappropriate for direct disposal. But what if they could be essentially stabilized by the geologic environment? Consider a repository such as the Waste Isolation Pilot Plant (WIPP), which was constructed within a salt basin. Brines in such a salt repository are fully saturated with $\mathrm{K}$ - and $\mathrm{Na}$ bearing chloride salt minerals in the salt formation, and the salt waste (except $\mathrm{LiCl}$ components if present in substantial amounts) would be considered thermodynamically compatible to the geochemical conditions in the repository. Salt creep and deformation in such a repository are greatly positive attributes and will have significantly favorable impacts on safe long-term waste isolation. Over thousands of years, the salt waste may become essentially encapsulated by the geologic salt formations and stabilized with no loss of radioactive materials outside of the repository boundary [17]. Currently, an investigation into such a disposal configuration is being carried out jointly by the INL and Sandia National Laboratory (SNL). Generic salt repositories are being considered, since it is unlikely that WIPP would be open long enough to accept salt waste from a pyroprocessing facility. The soonest that this concept could actually be tested would be in the next 10 years or so with salt currently being used to treat used EBRII fuel at INL. Total waste salt from EBR-II fuel processing is expected to be about $2 \mathrm{MT}$, which would occupy a volume of only $1 \mathrm{~m}^{3}$. Even a 100 MTHM per year pyroprocessing facility would generate a relatively small amount $\left(7 \mathrm{~m}^{3}\right)$ of salt waste per year.

\section{Conclusions}

An analysis of salt waste generation for both metallic and oxide used fuel in a pyroprocessing facility has been performed. Interesting insight into this problem has been obtained from relatively simple models and generalized treatment of processes. Fission product limits in the molten salt electrolyte of both the electrorefiner and oxide reduction unit appear to be the most restrictive-assuming that TRU elements would be recovered for new fuel fabrication. For the metallic fuel, first removing any bond sodium before the fuel is electrorefined is the key to reducing the amount of salt waste generated. Then the amount of salt waste generated would be dictated by the fission product concentration limit in the ER. Even at very high fission product chloride concentrations $(20 \mathrm{wt} \%)$, it is apparent that selective fission product separations processes can further reduce the amount of salt waste. Efficiency is defined as how much useful salt is carried along with the fission products into the waste stream. This efficiency must be higher for the metal fuel case compared to the oxide fuel case to provide overall benefit. That is largely because some of the fission products from oxide fuel partition into the oxide reduction salt and lead to waste generation from that unit operation. For metal fuel treatment, it is estimated that total salt waste generation would vary from 15 to $20 \mathrm{MT}$ /year (for a processing rate of $100 \mathrm{MT}$ fuel per year). For oxide fuel treatment, it is estimated that the total salt waste generation would vary between 8 and $14 \mathrm{MT} /$ year (100 MTHM fuel per year processing rate). Note that these fuels cannot be directly compared since the burnup and fission product content for each fuel type considered are different.

With respect to selective fission product separations processes, this paper presents both a motivation to design them into a pyroprocessing facility an indication to their limited benefit. Ultimately, a cost/benefit analysis would be needed for a specific pyroprocessing facility design to determine whether the salt should be disposed of in a nonselective or selective method. While there are durable ceramic and glass waste forms that can readily be produced with this waste salt, they increase the mass of waste by at least a factor of 10. Creating such waste forms would result in the total waste mass exceeding the mass of used fuel processed. Alternatively, it is suggested that direct disposal of the salt without a waste form in a salt repository may be the most logical path to pursue. A study is currently underway to assess the feasibility of direct disposal of salt waste in such an environment. If it appears to be sufficiently promising, the concept may be tested in the near term with waste salt from INL's electrorefiners. Ultimately, very compact waste disposal is possible by combining pyroprocessing with selective salt separations processes and direct disposal of the salt waste in a salt repository.

\section{References}

[1] K. C. Song, H. Lee, J. M. Hur, J. G. Kim, D. H. Ahn, and Y. Z. Cho, "Status of pyroprocessing technology development in Korea," Nuclear Engineering and Technology, vol. 42, no. 2, pp. 131-144, 2010.

[2] J. P. Ackerman, T. R. Johnson, L. S. H. Chow, E. L. Carls, W. H. Hannum, and J. J. Laidler, "Treatment of wastes in the ifr fuel cycle," Progress in Nuclear Energy, vol. 31, no. 1-2, pp. 141-154, 1997.

[3] L. J. Simpson and D. J. Wronkiewicz, "Evaluation of standard durability tests towards the qualification process for the glasszeolite ceramic waste form," in Proceedings of the 20th Scientific Basis for Nuclear Waste Management, W. Gray and K. Knecht, Eds., vol. 465, pp. 441-448, Materials Research Society, 1997.

[4] C. Pereira, "Production of sodalite waste forms by addition of glass," Ceramic Transactions, vol. 61, p. 389, 1997. 
[5] S. Priebe and K. Bateman, "The ceramic waste form process at Idaho National Laboratory," Nuclear Technology, vol. 162, no. 2, pp. 199-207, 2008.

[6] M. F. Simpson, K. M. Goff, S. G. Johnson et al., "A description of the ceramic waste form production process from the demonstration phase of the electrometallurgical treatment of EBR-II spent fuel," Nuclear Technology, vol. 134, no. 3, pp. 263-277, 2001.

[7] E. J. Karell, K. V. Gourishankar, J. L. Smith, L. S. Chow, and L. Redey, "Separation of actinides from LWR spent fuel using molten-salt-based electrochemical processes," Nuclear Technology, vol. 136, no. 3, pp. 342-353, 2001.

[8] S. D. Herrmann, S. X. Li, M. F. Simpson, and S. Phongikaroon, "Electrolytic reduction of spent nuclear oxide fuel as part of an integral process to separate and recover actinides from fission products," Separation Science and Technology, vol. 41, no. 10, pp. 1965-1983, 2006.

[9] S. X. Li, S. D. Herrmann, and M. F. Simpson, "Electrochemical analysis of actinides and rare earth constituents in liquid cadmium cathode product from spent fuel electrorefining," Nuclear Technology, vol. 171, no. 3, pp. 292-299, 2010.

[10] S. X. Li, S. D. Herrmann, K. M. Goff, M. F. Simpson, and R. W. Benedict, "Actinide recovery experiments with bench-scale liquid cadmium cathode in real fission product-laden molten salt," Nuclear Technology, vol. 165, no. 2, pp. 190-199, 2009.

[11] M. F. Simpson, T. S. Yoo, D. LaBrier, M. Lineberry, M. Shaltry, and S. Phongikaroon, "Selective reduction of active metal chlorides from molten $\mathrm{LiCl}-\mathrm{KCl}$ using lithium drawdown," Nuclear Engineering and Technology, vol. 44, no. 7, pp. 767-772, 2012.

[12] C. Pereira, M. C. Hash, M. A. Lewis, M. K. Richmann, and J. Basco, "Incorporation of radionuclides from the electrometallurgical treatment of spent fuel into a ceramic waste form," Materials Research Society Symposium Proceedings, vol. 556, p. 115, 1999.

[13] Y. Z. Cho, H. C. Yang, H. C. Eun, E. H. Kim, and I. T. Kim, "Characteristics of oxidation reaction of rare-earth chlorides for precipitation in $\mathrm{LiCl}-\mathrm{KCl}$ molten salt by oxygen sparging," Journal of Nuclear Science and Technology, vol. 43, no. 10, pp. 1280-1286, 2006.

[14] V. A. Volkovich, T. R. Griffiths, and R. C. Thied, "Treatment of molten salt wastes by phosphate precipitation: removal of fission product elements after pyrochemical reprocessing of spent nuclear fuels in chloride melts," Journal of Nuclear Materials, vol. 323, no. 1, pp. 49-56, 2003.

[15] Y. Z. Cho, G. H. O. Park, H. S. U. Lee, I. N. T. Kim, and D. S. Han, "Concentration of cesium and strontium elements involved in a $\mathrm{LiCl}$ waste salt by a melt crystallization process," Nuclear Technology, vol. 171, no. 3, pp. 325-334, 2010.

[16] B. J. Riley, B. T. Rieck, J. S. McCloy, J. V. Crum, S. K. Sundaram, and J. D. Vienna, "Tellurite glass as a waste form for mixed alkali-chloride waste streams: candidate materials selection and initial testing," Journal of Nuclear Materials, vol. 242, no. 1-3, pp. 29-37, 2012.

[17] Y. Wang, M. Simpson, J. Rath et al., "Closing the nuclear fuel cycle with salt," in Proceedings of the 13th International HighLevel Radioactive Waste Management Conference, Albuquerque, NM, USA, 2011. 


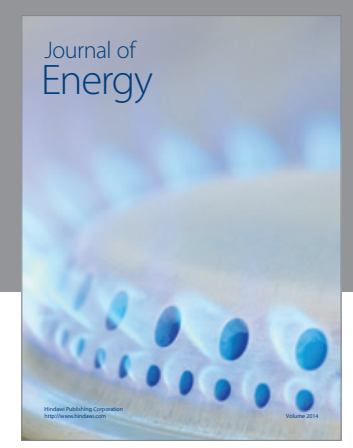

Journal of

Industrial Engineering
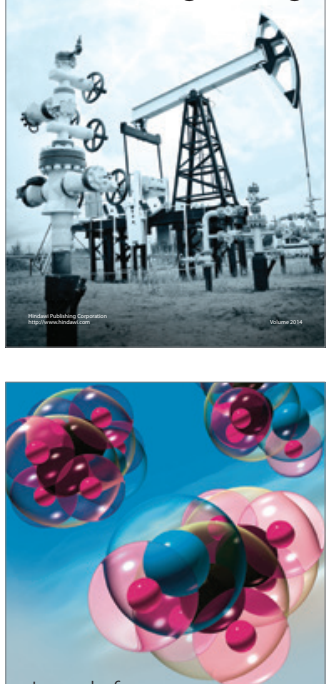

Fuels
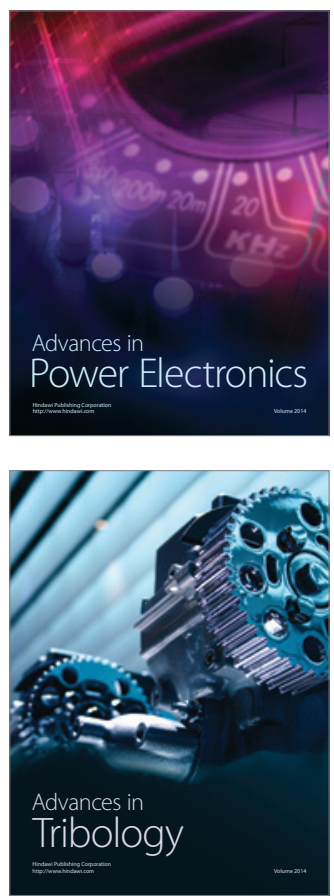

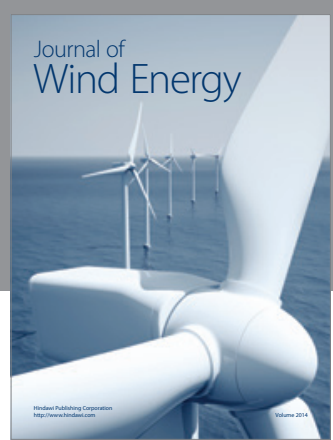

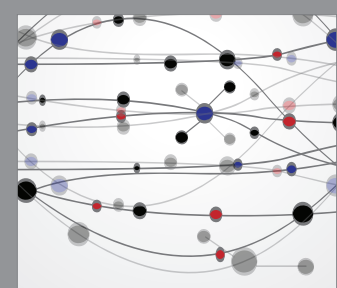

The Scientific World Journal

Submit your manuscripts at http://www.hindawi.com

Journal of

Structures
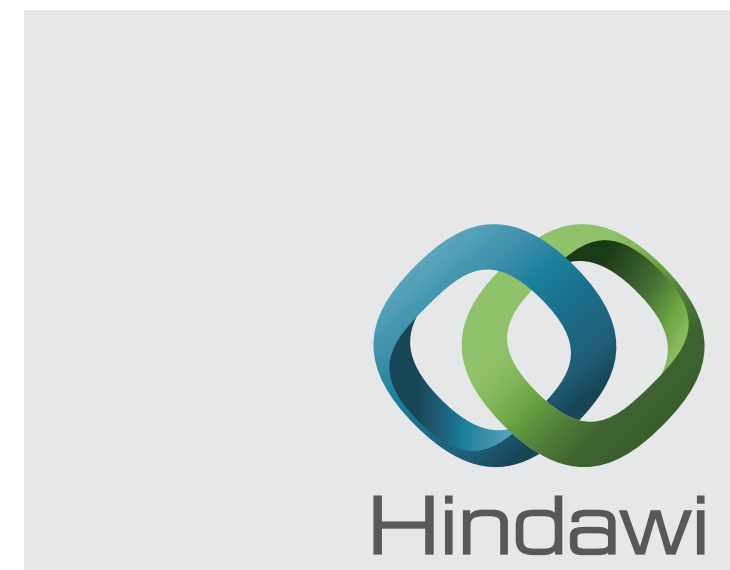

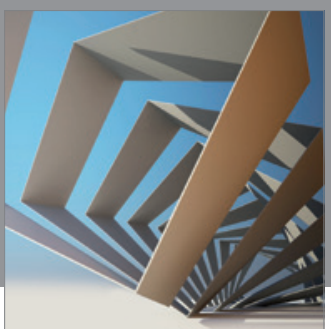

Rotating

Machinery
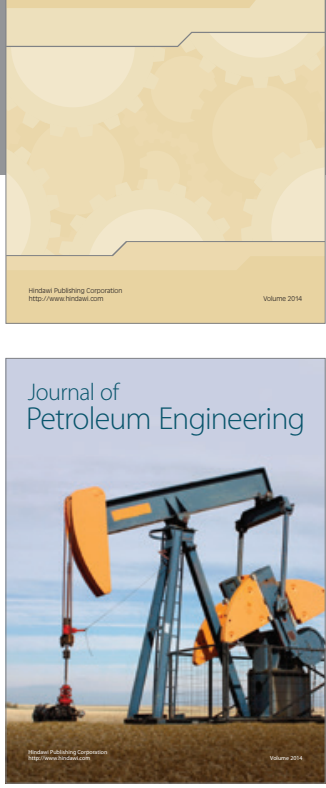

Journal of

Solar Energy
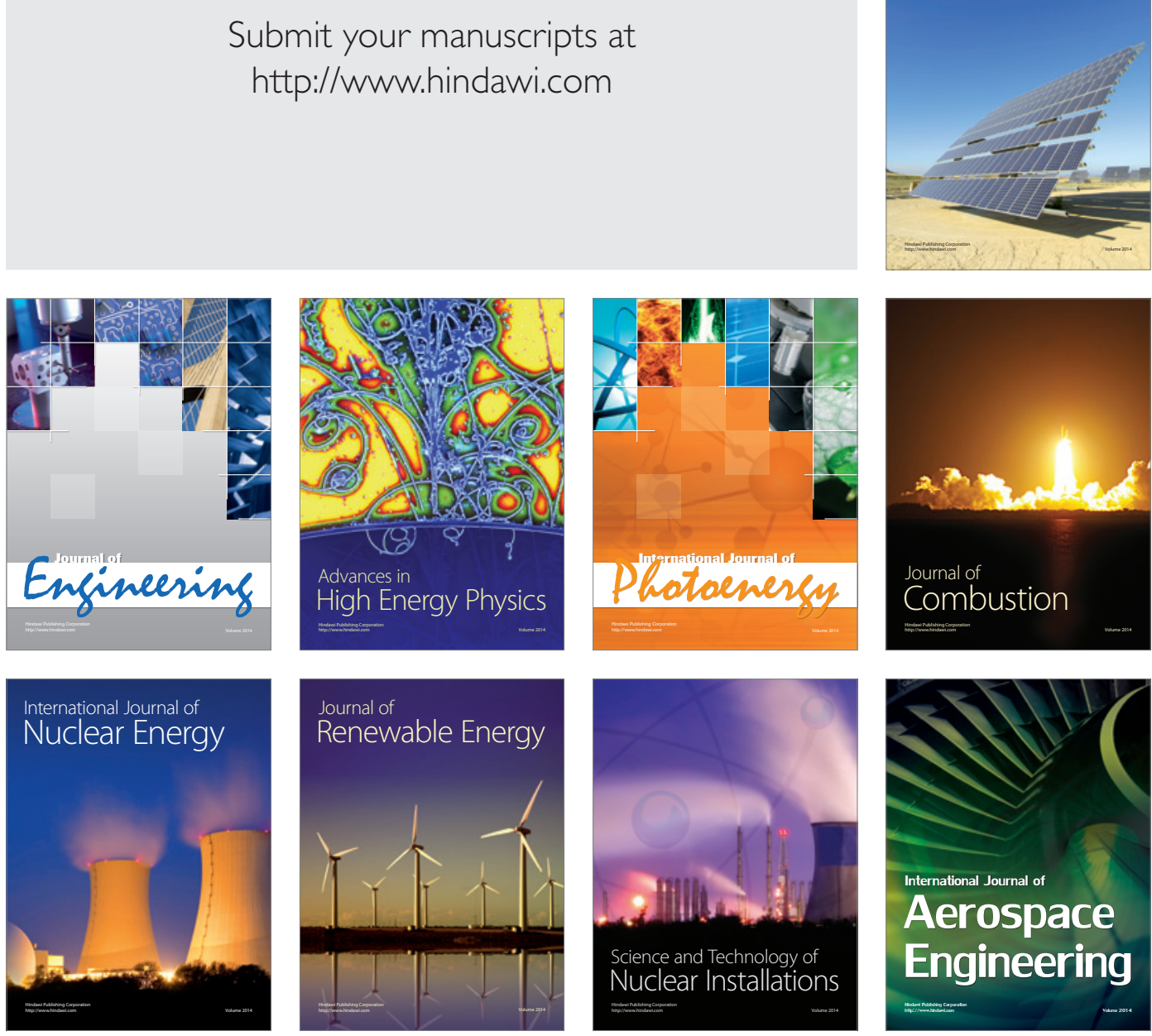